\title{
Pobreza y exclusión social: una aproximación al caso peruano
}

Pauvreté et exclusion sociale: une approche du cas péruvien

Powerty and social exclusion: the approach to a peruvian case

Iris Roca Rey y Belissa Rojas

\section{(2) OpenEdition}

Edición electrónica

URL: http://journals.openedition.org/bifea/6828

DOI: $10.4000 /$ bifea. 6828

ISSN: 2076-5827

\section{Editor}

Institut Français d'Études Andines

Edición impresa

Fecha de publicación: 1 diciembre 2002

Paginación: 699-724

ISSN: 0303-7495

Referencia electrónica

Iris Roca Rey y Belissa Rojas, "Pobreza y exclusión social: una aproximación al caso peruano », Bulletin de l'Institut français d'études andines [En línea], 31 (3) | 2002, Publicado el 08 diciembre 2002, consultado el 10 diciembre 2020. URL : http://journals.openedition.org/bifea/6828 ; DOI : https:// doi.org/10.4000/bifea.6828

\section{(2) $(\mathcal{Q} \Theta \Theta$}

Les contenus du Bulletin de l'Institut français d'études andines sont mis à disposition selon les termes de la licence Creative Commons Attribution - Pas d'Utilisation Commerciale - Pas de Modification 4.0 International. 


\title{
POBREZA Y EXCLUSIÓN SOCIAL: UNA APROXIMACIÓN AL CASO PERUANO
}

\author{
Iris ROCA REY, Belissa ROJAS
}

\section{Resumen}

Diversos trabajos han analizado el fenómeno de la exclusión social en sus múltiples dimensiones y su relación con la pobreza. En los países desarrollados, es donde más se ha investigado este tema. En estos casos se plantea que la exclusión social está relacionada al desempleo, la etnia (inmigrantes) y la edad (vejez). En el caso de los países en desarrollo como el Perú, la exclusión social es un fenómeno existente pero respecto de variables diferentes a las mencionadas. En efecto, las estimaciones realizadas con la información de la Encuesta ENAHO (IV trimestre 2001) permiten apreciar las diversas dimensiones en que se expresa la exclusión social en el Perú.

En este trabajo, se intentará plantear respuestas a preguntas tales como: ¿Quiénes podrían estar sufriendo de la exclusión social en el Perú? ¿De qué están excluidos? ¿Todos los pobres están excluidos? ¿La exclusión social los afecta a todos por igual? ¿Cuál es la diferencia entre un pobre excluido y uno que no lo está? ¿Es importante diferenciarlos? ¿Por qué? ¿Qué implica la exclusión social para un país? ¿Afecta esta exclusión a la auto-confianza y capacidad de superar los problemas asociados con la pobreza?

Palabras claves: grupos vulnerables, pobreza, exclusión social, Perú, movilidad social, desigualdad

\section{PAUVRETÉ ET EXCLUSION SOCIALE : UNE APPROCHE DU CAS PÉRUVIEN}

\section{Resumé}

Différentes études ont analysé le phénomène de l'exclusion sociale dans ses multiples dimensions et sa relation avec la pauvreté. La plupart des travaux ont été réalisés dans les pays développés. Ceux-ci proposent que l'exclusion sociale dans leur pays soit liée au chômage, à l'origine ethnique (immigrants) et à l'âge. Dans le cas des pays en voie de développement comme le Pérou, l'exclusion sociale existe mais elle est liée à des aspects différents. En effet, les estimations réalisées grâce à l'enquête ENAHO (IV trimestre 2001) montrent les différentes dimensions de l'exclusion sociale au Pérou.

Dans cet article, nous essaierons de répondre à des questions telles que : Qui souffre actuellement de l'exclusion sociale au Pérou? De quoi souffrent ceux qui sont exclus ? Les

* Por orden alfabético: Los Capulies 158. Urb. La Aurora Miraflores, Lima, Perú. Los Naranjos202, La Molina, Lima, Perú. E-mail: irisrocarey@ hotmail.com, belissar@yahoo.com 
pauvres sont-ils tous exclus ? L'exclusion frappe-elle tout le mondede la même manière ? Quelle est la différence entre un pauvre exclu et un qui ne l'est pas ? Est-il important de faire cette différence ? Pourquoi ? Quelles sont les implications de l'exclusion sociales? L'exclusion sociale affecte-t-elle la confiance en soi et la capacité de surmonter les problèmes liés à la pauvreté ?

Mots clés : Groupes vulnérables, pauvreté, exclusion sociale, Pérou, mobilité sociale, inégalité.

\section{POWERTY AND SOCIAL EXCLUSION: THE APPROACH TO A PERUVIAN CASE}

\section{Abstract}

The dimensions of the social exclusion phenomenon and its relation with poverty have been analyzed in many papers. Developed countries were the most concerned about this topic and conducted many researches on it. They propose that social exclusion is related to unemployment, ethnicity (immigrants) and age (elderly). In the case of developing countries, like Peru, social exclusion is an existent phenomenon but related to variables different from those of developed countries. In fact, the estimations made using the ENAHO Survey (2001, fourth trimester) show the different variables in which the social exclusion states in Peru.

In this paper, we will try to propose answers to questions such as: Who is suffering social exclusion in Peru? What are they excluded from? Are all the poor excluded? What are the differences between an excluded poor and a non-excluded one? Is it important make this difference? Why? What are the implications of social exclusion to a country? Does social exclusion affect self-esteem and the capacity to challenge problems associated with poverty?

Key words: Groupes vulnérables, pauvreté, exclusion sociale, Pérou, mobilité sociale, inégalité

\section{INTRODUCCIÓN}

Los nuevos patrones de desarrollo implementados en nuestros países han llevado a que las formas de producción, las instituciones y los valores tengan un fuerte impacto en los grupos de menores ingresos de la población. Si bien muchos países han alcanzado un desarrollo económico y tecnológico, que años atrás era inimaginable, el costo de este avance se refleja en la creciente desigualdad entre los ingresos. Quizás sean los países que partieron con un mayor nivel de pobreza los que se han visto más afectados, pero hoy en día existe una preocupación mundial por entender qué sucedió. Entre los muchos factores que pudieron ocasionar esta diferencia abismal de ingresos, está el hecho de que no todas las personas pudieron ser parte de los cambios que acontecían en su sociedad siendo excluidas en gran parte de los grandes beneficios que la modernidad aún ofrece.

En este sentido, estudiar la exclusión social ayuda a entender los elevados niveles de pobreza de países como el Perú. Existe una estrecha relación entre ambos aspectos. El análisis de la pobreza sólo a través de indicadores económicos, ha sido objeto de crecientes críticas en la literatura especializada (Gallie, 1998). Estas críticas apuntan no sólo a la baja confiabilidad y complejidad en la estimación de los ingresos de hogares campesinos, auto-empleados o con trabajos eventuales, sino a algo más fundamental; la multidimensionalidad de la pobreza de la cual los bajos ingresos son sólo un componente. 
Por otro lado, "estos indicadores no consideran las diferentes necesidades de las personas ni reflejan el contexto sociocultural específico de la sociedad particular". (PNUD, 1997) Por lo tanto, la estimación y análisis de la exclusión social permite conocer a aquellos grupos de la sociedad que sufren algún tipo de exclusión social de los servicios e instituciones propios de su entorno sociocultural; y también a aquellos que además de lo anterior, pertenecen a los estratos de bajos ingresos.

Como consecuencia de la multidimensionalidad de la pobreza, resulta necesario realizar un análisis sobre aquellos aspectos que generan vulnerabilidad entre las personas y acentúan su situación de pobreza. Este factor de vulnerabilidad se relaciona directamente con la exclusión social, un fenómeno que ha sido poco considerado en los países en desarrollo, mientras que en países como Francia ya se vienen trabajando los factores que estarían determinando que algunas personas se sientan excluidas de la sociedad.

En este sentido, el presente trabajo plantea una clara diferencia entre la definición de exclusión en países desarrollados y países en desarrollo. En países como Francia e Inglaterra la exclusión se define en términos de acceso al mercado laboral mientras que en países como el Perú, el fenómeno ocurre por el lado del consumo: servicios básicos, educación y salud, ya que el espacio social y económico no es homogéneo. La exclusión en este sentido, se va a dar por segmentos.

En el caso peruano, uno de los trabajos que analiza este tema es el realizado por Aramburú \& Figueroa (1999), en el cual se calcula un índice para determinar quiénes están siendo excluidos dentro de los pobres extremos, bajo la hipótesis que dicho grupo tiene mayores probabilidades de permanecer en niveles de pobreza.

El presente documento tiene como objetivo principal plantear el análisis de la exclusión social como una medida que contribuya a identificar a grupos vulnerables con mayores probabilidades de traspasar la línea de pobreza o bien de permanecer en ella. Además, al tratarse el caso de personas pobres y a la vez excluidas, se está identificando un sector de la población que necesita una mayor atención, debido a que vive en situaciones más desventajosas que el resto de personas. En este sentido, lo interesante de este estudio es reconocer que no sólo los aspectos económicos o temas relacionados a calidad de vida, influyen en la situación de pobreza de las personas, sino que también lo hacen temas relacionados con la vulnerabilidad.

En este sentido, en el caso de los últimos resultados presentados por el INEI, basados en la encuesta ENAHO del IV Trimestre del 2001, los resultados no se muestran muy alentadores. La pobreza total estaría bordeando el 55\% de la población total; mientras que la población en extrema pobreza se habría incrementado fuertemente llegando a representar el 24,4\% del total de población peruana (Herrera, 2002). Sobre la base de estas cifras, muchos estudios han volcado su atención acerca de cómo combatir este problema. Es por ello que este trabajo se centra en identificar a grupos excluidos socialmente en diferentes aspectos de sus vidas.

En los capítulos que se desarrollarán, se intentará plantear respuestas a preguntas tales como: ¿Quiénes podrían estar sufriendo de la exclusión social en el Perú? ¿De qué están excluidos? ¿Todos los pobres están excluidos? ¿La exclusión social los afecta a 
todos por igual? ¿Cuál es la diferencia entre un pobre excluido y uno que no lo está? ¿Por qué es relevante diferenciarlos? ¿Qué implica la exclusión social? ¿Afecta esta exclusión a la auto-confianza y capacidad de superar los problemas asociados con la pobreza?

Para poder responder a estas interrogantes, el trabajo se estructura de la siguiente manera. Primero se presentará el marco teórico con la evolución teórica acerca de las diferentes maneras de medir la pobreza, así como las diferentes definiciones que existen de exclusión social. Un tema importante que se discutirá será la diferencia entre exclusión social y pobreza, ya que no todos los pobres son excluidos socialmente, y viceversa. Asimismo, en esta sección se proponen diferentes definiciones de exclusión social con sus distintas formas de expresión: ¿quiénes están afectados o son susceptibles de serlo y cuáles son las formas de expresión de dicho fenómeno? Por lo tanto, es necesario reconocer la complejidad que existe al querer determinar quiénes, cuánto y de qué se encuentran excluidos.

Una vez presentada la discusión teórica acerca de qué se entiende por exclusión social y su estrecha relación con la pobreza; en el siguiente capítulo, se presentan las estimaciones realizadas para el caso peruano. En este sentido, para los diferentes conceptos analizados, se presentan los resultados con una breve explicación metodológica y su correspondiente análisis. Finalmente, se presentan las conclusiones sobre la base de lo hallado en este trabajo de investigación.

\section{LA EXCLUSIÓN SOCIAL Y SU MULTIDIMENSIONALIDAD}

En las últimas décadas se ha dado una creciente preocupación mundial por los altos niveles de pobreza y desigualdad en el mundo, posicionándose como un tema de vital importancia en la agenda de los países. Esta preocupación ha incentivado a que los especialistas se interesen por este tema, proponiendo nuevas definiciones y mecanismos de medición complementarios a la teoría tradicional. En este sentido, hoy en día, definir pobreza implica considerar a un significativo número de personas que se encuentran viviendo en circunstancias intolerables, en donde el hambre, las enfermedades y la opresión son parte de su vida diaria (Kambur \& Squire, 1999). Esto implica dejar de analizar solamente indicadores económicos para incluir aspectos que antes no habían sido identificados como factores condicionantes o causantes de este fenómeno.

Sobre la base de lo anterior y dado el mayor interés que los países le están dando al tema de la pobreza, se puede identificar un proceso evolutivo en la definición de este concepto. En este sentido, una de las primeras definiciones de pobreza se centró en el aspecto económico; es decir, ser pobre implicaba no tener los ingresos o bienes considerados como aceptables para poder vivir. Esta definición, por lo tanto, requería de un indicador acerca de los ingresos o gastos realizados con el fin de determinar cuántos pobres habían en un determinado lugar (Kambur \& Squire, 1999). Una de las primeras estimaciones fue la realizada por Rowntree en 1910, quién cálculo una línea de pobreza determinando cuál era el presupuesto mínimo que debía tener una persona, que residía en Nueva York, para vivir en condiciones aceptables (Kambur \& Squire, 1999).

En una segunda etapa, la concepción de pobreza se amplió incluyendo aspectos relacionados con la calidad de vida de las personas. Por lo tanto, definir pobreza pasó a 
involucrar aspectos que no habían sido considerados en el enfoque económico, reconociendo una estrecha relación entre pobreza y la falta de acceso a un paquete integral, el cual incluye acceso a la educación, a la salud, a la nutrición, al agua potable y a servicios sanitarios (Unicef, 2000). En este sentido, medir la pobreza ha dejado de ser sólo un estudio de cifras macroeconómicas de un país, sino que también ha pasado a ser un análisis de las personas, porque son justamente ellas quiénes importan y sufren las consecuencias de este fenómeno (Haq).

Si bien este segundo enfoque engloba en su definición al primero, acercándose un poco más a una definición más real de lo que pobreza puede significar, aún deja de lado algunos aspectos importantes que están siendo recogidos en una visión más amplia de pobreza. En este sentido, los pobres, por el simple hecho de contar con menores recursos, perciben un mayor riesgo; es decir, son víctimas de eventos que escapan de su control (enfermedades, violencia, desastres naturales, etc.) y que agravan su situación económica, debilita su capacidad de negociar y aumenta su sensación de malestar (Banco Mundial, 2001). Por lo tanto, al carecer de los medios necesarios para protegerse adecuadamente frente a estos eventos, los pobres se hallan en situación de mayor vulnerabilidad que el resto de la población (Kanbur \& Squire, 1999). Esta mayor vulnerabilidad se encuentra estrechamente relacionada con el tema del derecho a voz, el riesgo, la inseguridad, sentirse indefenso, falta de medios para resolver sus problemas y la exclusión social: no acceden a los servicios a los que accede el resto de la población y muchas veces no están en capacidad de ejercer sus derechos (Banco Mundial, 2000).

El concepto moderno de la exclusión social tiene por lo menos dos antecedentes. El primero de ellos son los estudios sobre los efectos del desempleo en los vínculos con la comunidad iniciados en 1933 en el poblado de Marientahl en Austria por Jahoda et. al. los que han sido continuados por autores europeos concernidos con los efectos sociosicológicos del desempleo (Paugam en Francia, 1991 y Gallie en Inglaterra, 1998). La segunda fuente son los estudios antropológicos de Lewis en México y Guatemala sobre "La Cultura de la Pobreza" en los años 60.

Ambas vertientes parten de estudiar hogares e individuos pobres para, a partir de estos identificar otras dimensiones relacionadas con el contexto social y cultural de la vida familiar y comunitaria de los más pobres, enfatizando ambas perspectivas la falta de integración de estos hogares/individuos con la vida y los recursos institucionales de su medio. La exclusión social se puede observar en tres dimensiones: lo están,

- Relatividad: las personas están excluidas de algo en relación con otras que no

- Agencia: Las personas se auto-excluyen o bien otros las excluyen y

-Dinámica: Existen grupos con pocas posibilidades para el futuro no sólo para ellos sino para sus hijos. La exclusión social se puede transmitir entre generaciones (Atkinson \& Hills, 1998). Son individuos atrapados en una posición de ingreso relativo menor (Bourgignon, 1999).

Estos tres elementos deben ser considerados en el análisis empírico de la exclusión social.

Las sociedades contemporáneas experimentan un crecimiento de ciertos sectores de la población cuya calidad de vida y oportunidades de participar en la sociedad han 
sido disminuidas o bloqueadas. No tienen acceso a los beneficios de las instituciones y servicios sociales encontrándose aislados y marginados. En el caso de las sociedades industrializadas este fenómeno se encuentra asociado al desempleo, a la migración ilegal, a barreras étnicas, a la vejez y a la falta de integración de los jóvenes de ciertos sectores urbano-populares (Gallie, 1998). A este fenómeno creciente se le ha dado el nombre de exclusión social. Esta se puede definir como un proceso mediante el cual los individuos están excluidos completa o parcialmente de la participación en la sociedad en donde viven; lo cual podría implicar la ruptura de los lazos sociales (Arjan de Haan, 1997).

La exclusión social tiene un impacto no sólo en el nivel de vida o la calidad de vida de las personas que pertenecen a una sociedad que los margina sino un efecto psicológico sobre las mismas. Estas personas sienten que no pertenecen a la sociedad y que incluso es ella misma la que no les permite ingresar y/o no le interesa incluirlos "Agencia". Es por este motivo que se dice que la exclusión social va más allá del término "pobreza", y se refiere más bien al sentimiento de marginación (Democratic catalog, 1995). La exclusión llega a afectar hasta la autoestima de las personas, lo cual se ve claramente en el caso del desempleo (Britton, 1998).

Si bien este análisis se orienta principalmente a determinar el nivel de exclusión para los más pobres de la población, resulta importante aclarar que este fenómeno tiene la característica de no ser exclusivo de los estratos de bajos ingresos, es un concepto que abarca a un grupo mayor de personas. Por lo tanto, se debe tomar en cuenta que una parte importante de la sociedad ha sido excluida socialmente por contar con características particulares respecto al resto de la sociedad (relatividad). Estas pueden ser físicas, económicas, étnicas, religiosas, ideológicas y pueden incluir aspectos como desempleo, pobreza, discriminación racial, edad, sexual y nivel de educación, entre otros (University of Durham). Partiendo de la aclaración anterior, es posible comprender porqué algunos autores sugieren que no hay una definición precisa de exclusión social.

\section{1. ¿Qué factores causan la exclusión social?}

El sentimiento de marginación que provoca la exclusión social ha ocasionado que muchos países se preocupen por estudiar y entender los motivos por los cuales se han visto excluidos ciertos sectores de su población y por qué existen grupos aparentemente entrampados en la pobreza sin posibilidad alguna de movilidad social. Por ejemplo, en el Reino Unido se han planteado varias razones por las cuales estos grupos no están en capacidad de desarrollar su potencial y participar en los beneficios y oportunidades que ofrecen las instituciones que rigen sus vidas o de considerarse ellos mismos iguales a los otros miembros de la sociedad (University of Durham). De hecho, ¿qué factores causan la exclusión social?

En la literatura referida a las sociedades industrializadas el principal determinante de la exclusión social es el desempleo. Aún cuando existan sistemas de seguro o compensación por desempleo en el "Welfare State", que protegen a los trabajadores de una brusca disminución en los ingresos y a los desempleados, muchos de los que viven por su cuenta (y mayormente los varones) presentan altos niveles de exclusión social y stress emocional (Gallie, 1998). 
Un segundo factor asociado a la exclusión social es la edad; en países con estructuras por edad con un alto número de ancianos, estos experimentan altos niveles de exclusión social en términos de su integración a la vida comunitaria más allá de sus parientes inmediatos (Hicks, 1998). Paradójicamente, ciertos sectores de los jóvenes presentan también altos niveles de exclusión social. Este parece ser un fenómeno de las periferias urbanas (inner city) de las grandes ciudades en las que se concentran minorías étnicas o "ghettos" con altos niveles de inconducta social y violencia. En esa medida se encuentran excluidos de una vida sana y segura, de servicios preventivos de salud, de una educación con calidad y de un empleo estable.

Finalmente, un tercer grupo relacionado con altos niveles de exclusión social son los inmigrantes ilegales, especialmente los que pertenecen a grupos étnicos con marcadas diferencias raciales y culturales respecto de los grupos dominantes. Para estos sectores su etnicidad y su condición de ilegales bloquean su acceso a una serie de servicios y prestaciones sociales que sí están disponibles para los nativos o residentes legales (Altamirano, 1990). Las políticas de disminución de cuotas migratorias y de cierre de fronteras de muchas economías industrializadas, ha contribuido a agravar este problema.

Sin embargo, esta definición de la exclusión social se aplica principalmente a sociedades industrializadas en las que la mayoría de la población tiene acceso y utiliza servicios básicos, de salud y de educación. En caso de desempleo, el Estado provee un seguro por lo que la exclusión no se da por el lado de los ingresos y niveles de vida insuficientes, sino para el impacto psicológico en la autoestima de las personas desempleadas así como su marginación en cuanto el desempleo afecta sus redes sociales. En el caso de los países en desarrollo, la situación es totalmente diferente. El Estado no logra proveer los servicios básicos necesarios a la mayoría de la población ni los servicios de salud y educación. En este sentido, existe una desigualdad de oportunidades en la población que en el futuro se traduce en una desigualdad de ingresos, afectando evidentemente en el interin, su capacidad de tener un buen empleo. Sin embargo, resulta importante comprender, que si bien el aspecto psicológico también va a estar presente en estos países, su importancia se ve opacada al tratarse la exclusión por ejemplo de servicios básicos como el agua potable, el desagüe y la exclusión de servicios de salud. Enfocado, por ejemplo, desde el punto de vista de la niñez, el factor psicológico queda relevado si se trata de niños desnutridos, enfermos, etc.

La exclusión respecto de la edad en países en desarrollo no ocurre de la misma manera que en sociedades industrializadas ya que, para empezar, las pirámides de edad son distintas. La población en los países en desarrollo es mucho más joven y la proporción de personas de edad es menor que en los países industrializados por lo que este fenómeno no resulta el más crítico. En general, las personas de edad excluidas son aquellas que pertenecen a hogares pobres, es decir, no tienen los ingresos suficiente para mantener un nivel de vida mínimo o bien no tienen quien se ocupe de ellas.

Sin embargo, por el lado de las poblaciones más jóvenes, existe en países como el Perú, grupos de jóvenes vulnerables a fenómenos como la violencia, las drogas y la prostitución. Estos jóvenes por lo general, no acceden a la educación y pertenecen a los hogares más pobres del país. En el Perú, existe un fenómeno de desigualdad muy 
marcado en cuanto al acceso a oportunidades que permitan a las personas tener un nivel de vida aceptable.

En cuanto al enfoque de migración y al aspecto étnico, resulta importante comprender que, en el Perú, dada la centralización, existe un efecto migración hacia la capital. Históricamente, el Perú es un país mestizo, de diferencias marcadas étnicamente principalmente entre los pobladores de la Sierra, la Selva y Lima Metropolitana. En los años ochenta se dio un fenómeno de fuerte migración debido al terrorismo. Miles de campesinos huyeron de sus tierras no sólo por la pobreza sino por la violencia y la amenaza de los grupos terroristas creándose subculturas en la ciudad de Lima. Al igual que países europeos ocurrió con los inmigrantes de países africanos y árabes, dada la pobreza de esta población inmigrante, se les asoció con un mayor volumen de violencia y desorden en las calles. En este sentido, surgió la exclusión étnica versus este sector de la población, aún sin ser extranjeros como ocurrió en Europa. Ello se aplicaría por el hecho de que el Perú es un país pluricultural en el que la identidad nacional no es la misma para los diferentes grupos étnicos de la población.

\section{2. Procesos que favorecen la exclusión social}

Así como la exclusión social afecta a grupos diferentes, también está influenciada por diferentes procesos, medidas económicas y de política social. Estos pueden operar básicamente a dos niveles: a nivel de la sociedad o cultura dominante y a nivel de las políticas y programas sociales del gobierno. De aquí surge la siguiente pregunta: ¿cuáles son los procesos que favorecen la marginación y la exclusión? La respuesta requiere analizar tres aspectos de las políticas económicas y sociales:

- Los marginados son quienes sufren las consecuencias de muchas de las políticas económicas que se aplican en los países con problemas de inflación o balanza de pagos.

- Los programas sociales, susceptibles de ser puntos de apoyo para lograr su desarrollo y la inclusión social, no siempre son la prioridad de los gobiernos. Al respecto es importante determinar si las barreras de acceso a estos programas son por el lado de la oferta (cobertura limitada y calidad deficiente) o por el lado de la demanda (barreras geográficas, de información, de costos y/o culturales). Este factor será analizado en el presente documento.

- La restringida solidaridad entre las personas que no guardan un vínculo de parentesco o amistad es un valor social poco desarrollado (especialmente en sociedades como la peruana) con lo cual el aporte social voluntario, de los que más tienen y las empresas, no es muy alto (García Nieto, 1997)

Todos estos elementos pueden llevar a un incremento de este fenómeno en la sociedad. Además de las presentadas anteriormente, existen otras razones que explican la exclusión social.

En casi todas las sociedades multiétnicas, el proceso de modernización y expansión del mercado no ha garantizado para los grupos nativos, su incorporación a los beneficios de ésta. Por ejemplo, en diversos trabajos recientes sobre los grupos nativos de la Amazonía peruana se encuentran indicadores de salud, educación, saneamiento, 
etc. que están entre 3 a 5 veces por debajo de los promedios nacionales, incluso muy por debajo de los que tienen los grupos urbanos calificados como pobres (Brack \& Mora, 1998). La relación entre la exclusión social y el aspecto étnico y geográfico serán analizados en el presente documento.

Aunque la mayoría de limeños no se consideran racistas, y este tema ha sido cuidadosamente omitido de la investigación académica reciente, la evidencia estadística estaría contundente a favor de la existencia de correlación entre exclusión, pobreza y pertenencia a etnias amazónicas y andinas.

Una dimensión cultural que es de vital importancia es el grado de aceptación o rechazo de los grupos incluidos (o de la cultura dominante) sobre los excluidos. La actitud de rechazo de parte de los sectores económica y culturalmente dominantes hacia los grupos excluidos puede estar enraizada en su mentalidad y cultura aún de manera implícita, lo que dificulta la tolerancia y el apoyo político a programas y medidas que promuevan la inclusión social. En casos extremos estas actitudes de rechazo pueden llevar a la violencia y al racismo, plagas de las que la sociedad moderna no parece haberse librado.

\section{LA EXCLUSIÓN SOCIAL Y LA POBREZA: ¿SON CONCEPTOS DIFERENTES?}

La exclusión social es la parte de la trampa o círculo vicioso de la pobreza e implica altas posibilidades de distorsión dentro de la pobreza. Así, un individuo puede ser excluido sin estar contabilizado como pobre. Este caso sería el de los llamados "nuevos ricos" que si bien tienen un nivel de ingresos elevado, perteneciendo incluso al decil más alto, pueden ser excluidos de la "alta sociedad" justamente por tratarse de "nuevos ricos". Probablemente personas sin un apellido "importante" o con costumbres distintas, marginados por estas razones no económicas.

Sin embargo, es cierto que los grupos más pobres son más susceptibles a ser excluidos. La inclusión en redes informales de soporte y el capital social abren oportunidades a otras formas de capital que pueden ser consideradas como recursos para disminuir su pobreza o vulnerabilidad en ambientes rurales o urbanos, ellos también disminuyen el impacto en el componente de la trampa de la exclusión (Grootaert, 1998). Por ejemplo, el desarrollo de las cooperativas en grupos pobres ha servido para ayudarlos a combatir la pobreza al unir sus esfuerzos de manera organizada para integrarse en el mercado.

Resulta muy importante diferenciar los conceptos claramente. En efecto, ¿cuál es la diferencia entre pobreza y exclusión?

Los conceptos de pobreza y exclusión social están relacionados pero es importante señalar que no son lo mismo. Las personas pueden ser pobres sin estar o sentirse socialmente excluidas y viceversa. Por ejemplo, en el caso de desempleo, éste puede causar pobreza y eventualmente la exclusión, pero esta podría evitarse si las redes de apoyo familiar son fuertes. De otro lado, el acceso a un empleo o a un trabajo no asegura la inclusión social, como lo demuestra el caso de inmigrantes ilegales en USA, o simplemente si se trata de un trabajo eventual. Es decir, el desempleo puede ser una causa de exclusión social pero el empleo no necesariamente asegura la inclusión social. 
Otra dimensión a tomar en cuenta radica en el hecho de que muchas personas pueden ser pobres pero el significado y la percepción de la exclusión y pobreza varía entre ellos. En el caso de los grupos étnicos menos integrados, pueden ser pobres desde los estándares urbano-occidentales, pero encontrarse y sentirse integrados a instituciones y redes culturales propias hace que ellos se sientan incluidos al grupo étnico al cual pertenecen, lo cual finalmente es lo más importante para ellos. Por ejemplo, los latinos en Estados Unidostienen su propio grupo cultural, incluso pueden ser vistos como una amenaza por parte de los grupos nativos o first generation. El proceso de modernización no mejora significativamente la pobreza en estos grupos pero aumenta su exclusión social al ponerlos en contacto y competencia con grupos más occidentalizados.

La literatura es amplia en lo que respecta la distribución social y los conflictos dentro de los grupos y la interacción entre los grupos. A. Sen (1987) discute acerca de las capacidades y el concepto de exclusión social y realiza una distinción entre exclusión activa y pasiva. Entre estos dos tipos de exclusión, la primera es la exclusión deliberada de algunas personas con respecto de otros grupos para el acceso a igualdad de oportunidades, mientras que la segunda es una exclusión no voluntaria, dada por las condiciones externas, como lo sería en el caso de los pobladores ashaninkas, la falta de acceso a carreteras.

En resumen, el análisis de la dinámica de la pobreza podría ser completamente diferente dependiendo de si se observa más la exclusión activa o pasiva, ya que la exclusión social cubre un espectro de desigualdad socioeconómica así como otras segregaciones sociales. Esta diferenciación resulta fundamental al diseñar políticas de inclusión para aquellos más vulnerables ya que deben considerar el tipo de exclusión que enfrentan en su estrategia.

Por lo tanto, el objetivo debe ser examinar las interrelaciones entre exclusión y pobreza a fin de establecer políticas efectivas para disminuirla. El presente trabajo constituye un esfuerzo alineado con este fin.

\section{3. ¿CÓMO MEDIR LA EXCLUSIÓN SOCIAL?: METODOLOGÍA Y RESULTADOS}

\section{1. Metodología (1)}

En este trabajo, se ha presentado la exclusión social como un aspecto multidimensional, donde determinar quiénes, cómo y de qué están excluidos es un reto bastante grande. Sin embargo, la importancia radica en la estrecha relación que tiene la exclusión social con la pobreza, ya que visto como un indicador adicional a los tradicionalmente utilizados, la utilidad de analizar la exclusión social está en que esta muestra aspectos de la dinámica del proceso de pobreza: se debe prestar mayor atención a procesos sociopolíticos que hacen que grupos de personas se tornen vulnerables al caer en una pobreza crónica (Das Gupta, 1999). Es decir, los grupos de personas excluidas

(1) Características de la data: 1) Encuesta ENAHO IV trimestre de 2001, 2) Tamaño de la muestra: 18179 hogares a nivel nacional y 3) Nivel Inferencia Nacional, Urbano, Rural, Regional: costa, sierra y selva, Área Metropolitana de Lima y Callao. 
no necesariamente son también pobres. Justamente lo interesante de este indicador radica en que identifica a grupos no pobres pero con niveles elevados de vulnerabilidad que podrían llevarlos a una situación de pobreza en el futuro.

A raíz de lo anterior, medir la exclusión social se presenta como una alternativa para reducir los riesgos futuros de caer en pobreza. Si bien existe literatura acerca de la exclusión social a nivel teórico, no sucede lo mismo cuando se quiere conocer cómo es que se puede medir y quiénes están más excluidos que los demás. A pesar de este obstáculo, en este trabajo se ha tratado de identificar grupos vulnerables con el fin de contribuir en el análisis de la pobreza de este país. Es importante señalar que en el Perú solo se conoce el trabajo de Aramburú y Figueroa (1999), el cual calcula un índice de exclusión social basado en la metodología presentada en el Reporte de Desarrollo Humano de Estonia (PNUD, 1997). Este índice se presenta como una nueva aproximación a la medición de exclusión social; no obstante, presenta ciertas ventajas y limitaciones que nos llevaron a identificar grupos excluidos socialmente de manera separada; es decir, los resultados hallados no han sido agregados en un índice.

La revisión teórica ha dejado en claro que una persona puede estar excluida de uno o más aspectos de la vida social, política, económica o cultural, de su sociedad. Por lo cual, son muchos los factores que pueden ser analizados. Sobre la base de la encuesta ENAHO (2001) se han identificado aspectos relacionados con la incidencia de pobreza, calidad de vida y vulnerabilidad, con el fin de hallar grupos de personas que se encuentran excluidas socialmente. Asimismo, se han seleccionado tres criterios para agrupar a las personas que serán analizadas. Es decir, si se quiere saber quiénes están excluidos de los servicios de salud, lo primero es determinar en la encuesta ENAHO la pregunta que brinde información referente a quiénes han sido marginados de este servicio. Luego, habiendo escogido la pregunta se pasa a agrupar a aquellas personas que fueron excluidas y a quienes no, bajo tres criterios:

- el dominio geográfico (2),

- la lengua materna (3); y,

- los niveles de ingresos (4).

Dicha diferenciación sería útil en la medida que permitiría plantear alternativas de solución orientadas a grupos específicos vulnerables. De esta manera, se estaría determinando quiénes están excluidos de salud y al mismo tiempo se conoce en dónde se ubican estos grupos con mayores niveles de exclusión. Por otro lado, si bien el Perú no se considera un país racista es importante conocer si los diferentes grupos étnicos —basados en su lengua de origen — tienen las mismas oportunidades que el resto de la nación. Asimismo, se relaciona la medida de exclusión con el tema de la pobreza al realizar un análisis según el nivel adquisitivo de las personas. La nueva definición de

(2) La información se agrupa en 8 sectores: Costa Norte, Costa Centro, Costa Sur, Sierra Norte, Sierra Centro, Sierra Sur, Selva, Lima Metropolitana.

(3) La lengua materna se ha utilizado como una aproximación a los grupos étnicos según su lengua de origen: castellano, quechua, aymara, otras lenguas nativas e idioma extranjero.

(4) Como consecuencia de la desigualdad de ingresos se calculó el Decil de ingresos para ubicar a la población de acuerdo con ello. 
pobreza, en donde la vulnerabilidad de las personas se ha convertido en un factor primordial, implica que ya no sólo es importante contar con ingresos necesarios sino poder acceder a servicios que son esenciales para el desarrollo de las personas. Bajo estos criterios de agrupación, se han analizado los aspectos de acceso a la educación, salud, servicios básicos de la vivienda, a los medios de comunicación y esparcimiento, con el fin de señalar grupos vulnerables en diferentes aspectos de la vida de las personas.

\section{1. 1. Educación}

Se calculará la exclusión de la educación primaria y secundaria tomando en consideración que estudios realizados demuestran que las personas que no cuentan con educación primaria tienen mayores probabilidades de caer o mantenerse en estado de pobreza. Usualmente se consideró que aquellos con educación secundaria completa no eran vulnerables de caer en pobreza y eventualmente estarían en condiciones de salir de ella. Sin embargo, se ha planteado que la secundaria completa ya no sería un factor suficiente que lo garantice.

Por otra parte, los jefes de hogar sin educación primaria y/o secundaria tienen un impacto intergeneracional negativo en sus hijos, afectan el desarrollo de su potencial humano el cual es menor que el de aquellos con padres educados (Aldaz-Carrol \& Moran, 1999).

La educación está ligada al empleo y este a la pobreza. De esta manera, la falta de educación en una persona expone su vulnerabilidad a caer en estado de pobreza. Así, resulta importante identificar a aquellas personas que están excluidas de la educación ya que son un grupo altamente vulnerable.

En el presente trabajo se calculará la exclusión de la educación primaria para personas mayores de 12 años, ya que a esa edad se esperaría que un persona ya haya terminado la primaria. En esta sentido, a aquellos que no hayan terminado la primaria después de los 12 años, se les considerará excluidos de la educación. Para el caso de la secundaria se considerará como excluidos a aquellos que teniendo 18 años o más no tienen educación secundaria completa.

\section{1. 2. Salud}

La medición de la exclusión de los servicios de salud resulta de vital importancia en la medida que el acceso a los servicios de salud forma parte de las condiciones que deben satisfacerse para tener un bienestar mínimo. En el presente trabajo se mide la exclusión de los servicios de salud en términos del acceso y el uso de los servicios de salud. Este factor es importante en la medida que resulta relevante diferenciar aquellos que no utilizan servicios de salud porque no tienen acceso a ellos de aquellos que voluntariamente deciden no utilizarlos. En este sentido, la elección voluntaria de no acudir a centros de salud podría explicarse por razones de ingresos como por razones culturales.

En el presente documento se calculará el grado de exclusión a los servicios de salud tomando en cuenta a aquellos individuos que, estando enfermos, no han utilizado servicios de salud y cuáles son las razones que explican dicho comportamiento. 


\section{1. 3. Servicios básicos de la vivienda}

Otro aspecto que será analizado en este trabajo son las condiciones de la vivienda de la población en estudio. Al respecto, existen diferentes aspectos que pueden ser medidos cuando se quiere analizar las condiciones de un hogar. Para este trabajo, se ha elegido el acceso a servicios básicos de la vivienda — agua potable, desagüe, luz y teléfono- por dos razones fundamentales. En primer lugar, el tener acceso a estos servicios permite satisfacer otro tipo de necesidades. En el caso del agua potable y desagüe la relación está con los niveles mínimos de higiene, que los estándares de la mentalidad occidental han impuesto en nuestras sociedades, que a su vez disminuye los riesgos de enfermedades. Por su parte, la luz eléctrica, en hogares de extrema pobreza, puede ser un factor necesario para el desarrollo de actividades económicas dentro del hogar como alternativa de ingresos para la familia. Con respecto al servicio del teléfono, si bien no se considera una necesidad igual de básica que las anteriores, su elección se sustenta en la importancia que tiene como medio de comunicación para estos hogares con el resto de la población. Por su parte, en segundo lugar, el no acceso a estos servicios, en algunos casos, se puede explicar por la baja intervención del Estado. Es decir, una inadecuada política de gobierno que no le está otorgando a toda la población los servicios públicos que le corresponden como ciudadano.

En el caso de los servicios básicos de la vivienda se calculará la exclusión de los principales servicios como lo son agua, desagüe y luz. El teléfono, en el caso peruano, es un bien exclusivo por lo que no debe considerarse como básico.

\section{1. 4. Acceso a medios de comunicación y entretenimiento}

Hablar de exclusión es hablar de grupos marginados que no participan de algunos servicios que la sociedad les brinda o no se integran a ella opinando o informándose de los sucesos que acontecen en el día a día. Esto último lleva a que algunos grupos no se sientan parte de la sociedad, ya que no conocen qué está pasando a sus alrededores, contribuyendo a su exclusión social. Es por esta razón que en este trabajo se ha tratado de medir este aspecto a través del acceso a los medios de comunicación. Asimismo, los medios de comunicación no sólo mantienen informadas a las personas sobre hechos políticos, económicos, sino también sociales. Es decir, las personas necesitan distraerse y destinar sus horas de ocio en diversión y esparcimiento, y para ello necesitan información y medios de diversión.

En este sentido, el presente análisis se ha dividido en dos partes. Por un lado, se han diferenciado los medios de comunicación de lectura — periódicos y revistas-y los visuales y auditivos — televisión y radio — que no sólo informan noticias sino también contribuyen a brindar mayor información sobre formas de esparcimiento y diversión. En efecto, existen hogares que destinan parte de su dinero en comprar revistas o periódicos para mantenerse informados con los acontecimientos y de alguna manera es un medio de involucrarse con su sociedad. Por el otro, está el contar o no con medios auditivos y visuales de comunicación, como lo son la radio o la televisión. La importancia de estos medios radica en su masificación, que ha hecho que cada vez más personas puedan acceder a ellos. No obstante, aquellos hogares que aún no cuentan con alumbrado 
eléctrico se encuentran doblemente excluidos al no poder hacer uso de aparatos eléctricos como la televisión. Sobre la base de lo anterior, una manera de evitar esta doble contabilidad de exclusión, el análisis se basa en determinar aquellos hogares que cuentan con al menos uno de los dos — televisión o radio- considerándolos incluidos socialmente. Por lo tanto, aquellas familias que no tienen ninguno de estos dos artefactos son considerados excluidos. Por otro lado, en la segunda parte del análisis de esta sección, se han diferenciado a aquellas familias que destinan parte de sus ingresos a la diversión o esparcimiento (cine, $\mathrm{CD}$, juguetes, espectáculos deportivos, etc) de aquellas que no lo pueden hacer por razones económicas o culturales, y por consiguiente, para este trabajo, se consideran excluidas socialmente.

\section{2. Resultados}

\section{2. 1. Educación}

A nivel nacional, tal como se aprecia en la cuadro 1, aproximadamente $26 \%$ de la población mayor a 12 años está excluida de la educación primaria, esto es, no tienen primaria completa y alrededor del $42 \%$ de la población mayor a 18 años está excluida de la educación secundaria completa (5). Ello implica que tienen altas probabilidades de estar o caer en estado de pobreza y no tener los medios para salir de ella.

La situación es agravante para las mujeres que presentan un mayor índice de exclusión de la educación primaria y secundaria que los hombres. En efecto 31,22\% están excluidas de la educación primaria completa mientras que los hombres presentan un índice de 20,29\%. La exclusión de la secundaria completa es de 47,67\% para las mujeres mientras que, a pesar de ser una cifra considerable, en el caso de los hombres el 35,85\% de los hombres lo están. Resulta importante notar que la diferencia de género resulta un factor relevante para este análisis siendo un poco más de 10 puntos porcentuales.

\section{Cuadro 1 - Exclusión Social del Acceso a Educación Primaria y Secundaria Según Dominio Geográfico (En Porcentajes).}

\begin{tabular}{|c|c|c|c|c|c|c|}
\hline \multirow{2}{*}{$\begin{array}{c}\text { DOMINIO } \\
\text { GEOGRAFICO }\end{array}$} & \multicolumn{3}{|c|}{$\begin{array}{l}\text { Educación Primaria Incompleta } \\
\text { Edad mayor a doce años }\end{array}$} & \multicolumn{3}{|c|}{$\begin{array}{c}\text { Educación Secundaria Incompleta } \\
\text { Edad mayor a dieciocho años }\end{array}$} \\
\hline & Mujer & Hombre & Total & Mujer & Hombre & Total \\
\hline costa norte & 30.19 & 23.52 & 26.94 & 47.83 & 38.62 & 43.40 \\
\hline costa centro & 24.98 & 18.71 & 21.84 & 40.27 & 33.52 & 36.93 \\
\hline costa sur & 26.51 & 16.83 & 21.73 & 41.71 & 31.02 & 36.51 \\
\hline sierra norte & 56.35 & 40.38 & 48.65 & 79.86 & 69.22 & 74.73 \\
\hline sierra centro & 50.03 & 29.01 & 39.68 & 66.91 & 48.97 & 58.28 \\
\hline sierra sur & 40.12 & 22.02 & 31.28 & 57.27 & 38.56 & 48.30 \\
\hline selva & 36.01 & 26.90 & 31.29 & 60.32 & 50.21 & 55.10 \\
\hline Lima metropolitana & 14.41 & 7.50 & 11.11 & 27.01 & 16.54 & 22.00 \\
\hline Total & 31.22 & 20.29 & 25.87 & 47.67 & 35.85 & 41.93 \\
\hline
\end{tabular}

(5) El índice de exclusión de secundaria completa para personas mayores de 18 años incluye parte de los excluidos de primaria completa ya que una persona sin primaria completa, evidentemente no va a tener la secundaria completa. 
Por otro lado, a nivel regional, la Sierra Norte y la Sierra Central presentan los índices de exclusión respecto de la educación primaria más altos a nivel nacional, $48,65 \%$ y $39,68 \%$ respectivamente, y $74,73 \%$ y $58,28 \%$ respecto de la educación secundaria. Se puede notar que la exclusión de la educación secundaria es mayor que la de primaria y que las mujeres, una vez más, presentan un índice de exclusión más alto. Estos patrones se repiten para cada región lo que indicaría que para ellas resulta más difícil acceder a la educación más avanzada.

El caso de Lima Metropolitana es interesante no tanto en términos de magnitud ya que presenta los índices de exclusión más bajos (11\% de personas excluidas de la educación primaria completa y $22 \%$ de la secundaria completa) pero sí a nivel de género. El índice de exclusión de la educación primaria para las mujeres es casi el doble que el de los hombres $(14,41 \%$ versus $7,5 \%)$, y en la educación secundaria la exclusión para las mujeres es aproximadamente 10 puntos porcentuales mayor a la de los hombres (27,01\% versus $16,54 \%)$.

Por otro lado, aquellos con lengua materna uno diferente al castellano o idiomas extranjeros, presentan mayores índices de exclusión respecto de la educación primaria que aquellos de habla castellana (Ver Cuadro 2). Incluso las personas cuya lengua nativa es distinta al quechua y al aymara presentan un índice de exclusión de la educación primaria mayor a $(47,7 \%)$. El índice más bajo se encuentra en aquellos de habla extranjera (1,83\%). Ello se mantiene en el caso de la exclusión de la secundaria. En el caso de los sordomudos, no tienen acceso a la educación, lo que en este caso implicaría la falta de escuelas para personas con esta discapacidad.

\section{Cuadro 2 - Exclusión Social del Acceso a Educación Primaria y Secundaria Según Lengua Materna (En Porcentajes).}

\begin{tabular}{|l|c|c|c|c|c|c|}
\hline \multirow{2}{*}{ LENGUA MATERNA } & \multicolumn{3}{|c|}{$\begin{array}{c}\text { Educación Primaria Incompleta } \\
\text { Edad mayor a doce años }\end{array}$} & \multicolumn{2}{c|}{$\begin{array}{c}\text { Educación Secundaria Incompleta } \\
\text { Edad mayor a dieciocho años }\end{array}$} \\
\cline { 2 - 7 } & Mujer & Hombre & Total & Mujer & Hombre & Total \\
\hline castellano & 25.17 & 17.10 & 21.24 & 41.03 & 31.68 & 36.50 \\
\hline quechua & 49.23 & 29.38 & 39.38 & 67.08 & 48.74 & 58.16 \\
\hline aymara & 40.77 & 22.03 & 31.24 & 64.32 & 41.46 & 52.87 \\
\hline Otra lengua nativa & 53.87 & 42.68 & 47.75 & 80.25 & 59.79 & 69.47 \\
\hline inglés & 0.00 & 0.00 & 0.00 & 0.00 & 0.00 & 0.00 \\
\hline portugues & 2.90 & 8.24 & 4.29 & 45.69 & 9.71 & 37.26 \\
\hline otro idioma extranjero & 0.16 & 4.54 & 1.83 & 10.71 & 6.86 & 9.39 \\
\hline sordomudo & & 100.00 & 100.00 & & 100.00 & 100.00 \\
\hline Total & $\mathbf{3 1 . 6 7}$ & $\mathbf{2 0 . 5 4}$ & $\mathbf{2 6 . 2 1}$ & $\mathbf{4 8 . 2 2}$ & $\mathbf{3 6 . 3 4}$ & $\mathbf{4 2 . 4 5}$ \\
\hline
\end{tabular}

En el caso de los ingresos (6), el Cuadro 3 muestra que estos se encuentran aparentemente correlacionados con el acceso a la educación. Conforme los ingresos son menores la exclusión respecto de la educación aumenta, tanto de primaria como de secundaria.

(6) Para fines de este trebajo, la población ha sido agrupada en deciles de acuredo a su nivel de ingresos, donde el primer decil corresponde a familias con menores ingresos hasta llegar al décimo decil donde se encuentran las familias con mayores ingresos. 


\section{Cuadro 3 - Exclusión Social del Acceso a Educación Primaria y Secundaria Según Decil de Ingresos (En Porcentajes).}

\begin{tabular}{|l|c|c|c|c|c|c|}
\hline \multirow{2}{*}{ DECIL } & \multicolumn{3}{|c|}{$\begin{array}{c}\text { Educacion Primaria Incompleta } \\
\text { Edad mayor a doce años }\end{array}$} & \multicolumn{2}{c|}{$\begin{array}{c}\text { Educacion Secundaria Incompleta } \\
\text { Edad mayor a dieciocho años }\end{array}$} \\
\cline { 2 - 7 } & Mujer & Hombre & Total & Mujer & Hombre & Total \\
\hline Primer decil & 68.09 & 50.76 & 59.73 & 90.71 & 78.53 & 84.97 \\
\hline Segundo decil & 59.44 & 38.47 & 49.06 & 82.08 & 66.53 & 74.64 \\
\hline Tercer decil & 46.28 & 30.41 & 38.34 & 69.89 & 54.74 & 62.51 \\
\hline Cuarto decil & 39.93 & 24.06 & 31.86 & 62.03 & 46.51 & 54.23 \\
\hline Quinto decil & 32.53 & 20.66 & 26.56 & 53.58 & 38.05 & 45.86 \\
\hline Sexto decil & 26.34 & 16.62 & 21.67 & 43.38 & 33.83 & 38.76 \\
\hline Sétimo decil & 21.30 & 13.20 & 17.36 & 37.77 & 27.29 & 32.73 \\
\hline Octavo decil & 17.92 & 12.22 & 15.13 & 32.44 & 23.01 & 27.77 \\
\hline Noveno decil & 14.82 & 7.57 & 11.32 & 25.88 & 17.20 & 21.67 \\
\hline Décimo decil & 8.50 & 3.48 & 6.12 & 17.97 & 8.05 & 13.30 \\
\hline Total & $\mathbf{3 1 . 2 2}$ & $\mathbf{2 0 . 2 9}$ & $\mathbf{2 5 . 8 7}$ & $\mathbf{4 7 . 6 7}$ & $\mathbf{3 5 . 8 5}$ & $\mathbf{4 1 . 9 3}$
\end{tabular}

\section{2. 2. Salud}

El índice de exclusión social considera a aquellos enfermos que por alguna razón no asistieron a centros médicos. Resultan de interés razones de acceso, cultura e ingreso en la medida que revelan carencias. Sin embargo, también existe un grupo de enfermos que no se atendieron, porque no lo consideraron necesario. En este sentido, el cuadro 4 muestra los ratios de exclusión de acuerdo a las razones que los llevaron a prescindir de consultas médicas para curar su enfermedad.

Según la encuesta ENAHO, 37,86\% de las personas enfermas no se atendieron porque no lo consideraron necesario. Para efectos del análisis es factible suponer que en estos casos, la gravedad de la enfermedad no ameritaba atención en un centro de salud.

Bajo este supuesto, la principal razón por la que los enfermos no se atienden es cultural $(36,22 \%)$ y tan sólo $2,44 \%$ no lo hicieron por acceso, es decir, por que no contaron con un centro de salud cercano. Ello indicaría exclusión por el lado cultural, que estaría afectando el uso de centros de salud ya que existe un grupo de personas que decidió curarse con remedios caseros o al no tener confianza ni creer en la medicina occidental optó por no asistir a un centro a recibir atención médica. Ello resulta relevante en la medida que una política para mejorar las condiciones de vida en el aspecto de la salud debería considerar no sólo infraestructura sino también educación.

El aspecto cultural como razón para explicar el hecho de no usar atención médica es más elevado en la sierra y para la población de habla quechua, aymara u otra lengua indígena. Ello tiene sentido en la medida que estas personas viven principalmente en la sierra, donde a su vez se encuentran las zonas con mayor pobreza en el país. En este sentido, dotar a las comunidades de centros de salud que brindan servicios basados en los criterios de la medicina occidental, no contribuirá a que a grupos ubicados en la Sierra del país se atienda, ya que su decisión de no hacerlo se fundamenta en creencias culturales. Es por ello que este ratio de exclusión muestra una realidad diferente, donde la solución para incluir a estas personas al servicio de salud se aleja de construir centros de salud modernos que no respeten sus creencias. 
La segunda razón que explica que no se usen los servicios de salud, aun estando enfermo, es monetario $(23,48 \%)$; ya sea porque no contaban con efectivo para pagar la consulta o carecían de un seguro médico. Los índices más altos se presentan en la costa Norte y Sur, la Sierra Centro, la Selva y Lima Metropolitana. El alto índice en Lima Metropolitana reflejaría una alta desigualdad ya que, en términos de ingresos, Lima no es la zona de mayor pobreza del Perú como lo serían la Selva y la Sierra Central.

Cuadro 4 - Exclusión Social del Servicios de Salud por Problemas de Acceso, Dinero o Diferencias Culturales o porque no lo consideraron necesario (En Porcentajes).

\begin{tabular}{|l|c|c|c|c|}
\hline \multirow{2}{*}{ CRITERIO DE AGRUPACION } & \multicolumn{4}{|c|}{ Enfermos que no se atendieron por las siguientes } \\
& \multicolumn{4}{|c|}{ razones } \\
\hline \multicolumn{1}{|c|}{ DOMINIO GEOGRAFICO } & Acceso & Dinero & Cultura & $\begin{array}{c}\text { No fue } \\
\text { necesario }\end{array}$ \\
\hline Costa norte & 1.03 & 26.53 & 18.26 & 54.18 \\
\hline Costa centro & 1.21 & 18.80 & 26.61 & 53.39 \\
\hline Costa sur & 0.76 & 25.94 & 24.88 & 48.42 \\
\hline sierra norte & 2.27 & 19.54 & 40.27 & 37.92 \\
\hline sierra centro & 4.15 & 25.60 & 49.72 & 20.53 \\
\hline sierra sur & 3.29 & 18.08 & 51.98 & 26.66 \\
\hline selva & 3.89 & 26.02 & 35.03 & 35.07 \\
\hline Lima metropolitana & 0.28 & 26.58 & 17.10 & 56.04 \\
\hline Total & $\mathbf{2 . 4 4}$ & $\mathbf{2 3 . 4 8}$ & 36.22 & $\mathbf{3 7 . 8 6}$ \\
\hline \multicolumn{1}{|c|}{ LENGUA MATERNA } & Acceso & Dinero & Cultura & No fue \\
\hline castellano & 1.58 & 23.69 & 29.78 & 44.95 \\
\hline quechua & 3.96 & 24.67 & 45.11 & 26.27 \\
\hline aymara & 2.38 & 17.49 & 51.21 & 28.92 \\
\hline otra lengua nativa & 10.01 & 12.70 & 38.57 & 38.72 \\
\hline portugués & 0.00 & 5.14 & 42.70 & 52.16 \\
\hline otro idioma extranjero & 0.00 & 1.21 & 24.70 & 74.10 \\
\hline es sordomudo & 0.00 & 100.00 & 0.00 & 0.00 \\
\hline Total & $\mathbf{2 . 4 7}$ & $\mathbf{2 3 . 5 2}$ & 36.14 & $\mathbf{3 7 . 8 7}$ \\
\hline & Acceso & Dinero & Cultura & No fue \\
\hline Primer decil & 4.65 & 24.49 & 48.31 & 22.55 \\
\hline Segundo decil & 3.88 & 26.78 & 46.38 & 22.97 \\
\hline Tercer decil & 2.34 & 27.01 & 42.58 & 28.07 \\
\hline Cuarto decil & 2.21 & 25.48 & 37.83 & 34.48 \\
\hline Quinto decil & 1.81 & 28.88 & 31.77 & 37.55 \\
\hline Sexto decil & 1.39 & 26.23 & 31.65 & 40.74 \\
\hline Sétimo decil & 0.59 & 22.94 & 25.92 & 50.54 \\
\hline Octavo decil & 0.27 & 21.70 & 26.05 & 51.98 \\
\hline Noveno decil & 0.81 & 13.23 & 23.81 & 62.14 \\
\hline Décimo decil & 1.40 & 9.26 & 17.75 & 71.59 \\
\hline Total & $\mathbf{2 . 3 2}$ & $\mathbf{2 3 . 5 8}$ & 35.94 & 38.15 \\
\hline
\end{tabular}




\section{2. 3. Servicios básicos de la vivienda}

Los primeros resultados acerca del acceso a agua, desagüe, luz y teléfono varían de acuerdo con el bien analizado. No obstante, existe un patrón que se repite: sin importar el criterio utilizado para agrupar a los hogares — dominio geográfico, el Decil de los ingresos de cada hogar o la lengua materna-, el acceso a teléfono muestra los mayores niveles de exclusión, seguido del acceso a desagüe, agua y luz. Ello indicaría que contar con un teléfono en el hogar puede considerarse casi un lujo dejando de ser una necesidad primordial.

De esta manera, sin tener en cuenta el teléfono, la exclusión es más elevada respecto del desagüe $(52,29 \%)$, luego de la luz $(30,57 \%)$ y finalmente del agua $(36,71 \%)$, tal como se puede observar en el cuadro 5 (7).

Respecto del servicio de desagüe, los ratios de exclusión son muy elevados (más de $65 \%$ ) para la zona de la Sierra y la Selva. Tal como era de esperar, también lo son para la población de lengua quechua, aymara y otras lenguas indígenas (más de 64\%). Evidentemente, para los deciles de ingresos más bajos los niveles de exclusión son más altos: para los tres deciles más bajos la exclusión es más de $80 \%$.

En lo referente a la luz, el patrón es similar al anterior salvo para la Sierra Sur $(33,35 \%)$. Los ratios de exclusión para la Sierra Norte, Sierra Nentro y la Selva son mayores a 50\%. En lo referente a las lenguas nativas, los ratios más altos lo presentan las poblaciones quechuahablante y otras lenguas nativas $(42,42 \%$ y $85,06 \%$ respectivamente). Los deciles más bajos presentan los ratios de exclusión respecto de la luz más altos (más de $50 \%$ los tres deciles más bajos).

Finalmente, los ratios de exclusión del servicio de agua potable son mayores a $40 \%$ para la Sierra y la Selva es $61,81 \%$. En el caso de las lenguas nativas, el índice de exclusión más alto se presenta en las poblaciones de lenguas nativas distintas al quechua y aymara $(81,05 \%)$. En lo referente al ingreso, los deciles más bajos presentan índices de exclusión mayores a $50 \%$.

Como consecuencia de los resultados del cuadro anterior, con respecto al acceso al teléfono, en el siguiente cuadro se ha prescindido de este bien para determinar los niveles de exclusión de acuerdo al número de SBV a los cuales el hogar no accede. En el cuadro 6 se puede observar que, en promedio, un 21,6\% de los hogares peruanos no cuentan con ninguno de los tres SBV.

Por otro lado, existe una gran diferencia entre los niveles de exclusión e inclusión para los hogares: los que están ubicados en la Sierra y Selva del país, los que hablan lenguas nativas y los ubicados en el Decil más bajo de los ingresos, respecto del resto de familias.

En efecto, más de $40 \%$ de los hogares en la Sierra Norte y Selva del país, no tienen acceso a ninguno de los tres servicios. Por otra parte, al agrupar los hogares según lengua materna, el 74,64\% de los hogares que hablan otra lengua nativa no cuentan con ninguno de los tres SBV, y tan sólo el 7,56\% accede a ellos. Finalmente, los hogares ubicados

(7) Tal como se puede observar, los índices de exclusión totales respecto del agua, desagüe, luz y teléfono no son iguales al dividirse según los criterios de agrupación. Ello se explica porque en el caso de la lengua materna, no todos los encuestados respondieron las preguntas. 
Cuadro 5 - Exclusión Social según el Acceso a los Servicios Básicos de la Vivienda (En Porcentajes).

\begin{tabular}{|c|c|c|c|c|}
\hline $\begin{array}{l}\text { CRITERIO DE } \\
\text { AGRUPACION }\end{array}$ & \multicolumn{4}{|c|}{$\begin{array}{c}\text { Servicios Básicos de la Vivienda } \\
\text { (Agua, desague, luz) }\end{array}$} \\
\hline $\begin{array}{c}\text { DOMINIO } \\
\text { GEOGRAFICO }\end{array}$ & Agua & desague & luz & telf \\
\hline costa norte & 36.43 & 48.86 & 30.89 & 78.69 \\
\hline costa centro & 27.56 & 40.90 & 21.92 & 71.13 \\
\hline costa sur & 16.69 & 39.48 & 8.96 & 78.53 \\
\hline sierra norte & 43.18 & 79.32 & 70.00 & 97.04 \\
\hline sierra centro & 44.57 & 76.92 & 50.26 & 93.05 \\
\hline sierra sur & 41.19 & 66.23 & 33.35 & 86.28 \\
\hline selva & 61.81 & 77.88 & 52.81 & 92.88 \\
\hline Lima metropolitana & 20.99 & 19.27 & 2.26 & 46.33 \\
\hline Total & 36.71 & 52.29 & 30.57 & 75.31 \\
\hline LENGUA MATERNA & Agua & desague & Tuz & telf \\
\hline castellano & 33.05 & 45.45 & 26.10 & 69.95 \\
\hline quechua & 44.70 & 69.81 & 42.42 & 88.10 \\
\hline aymara & 43.58 & 64.53 & 25.53 & 94.11 \\
\hline otra lengua nativa & 81.05 & 92.44 & 85.06 & 96.68 \\
\hline inglés & 100.00 & 100.00 & 0.00 & 100.00 \\
\hline portugués & 0.00 & 0.00 & 0.00 & 0.00 \\
\hline otro idioma extranjero & 9.00 & 10.38 & 4.94 & 4.94 \\
\hline es sordomudo & 17.85 & 100.00 & 100.00 & 100.00 \\
\hline Total & 36.83 & 52.73 & 30.90 & 75.50 \\
\hline DECIL & Agua & desague & luz & telf \\
\hline Primer decil & 71.07 & 97.09 & 79.50 & 100.00 \\
\hline Segundo decil & 57.91 & 90.24 & 66.23 & 99.54 \\
\hline Tercer decil & 54.37 & 80.04 & 52.25 & 97.71 \\
\hline Cuarto decil & 42.51 & 65.23 & 35.76 & 95.32 \\
\hline Quinto decil & 43.05 & 56.43 & 27.51 & 87.39 \\
\hline Sexto decil & 32.32 & 45.61 & 16.68 & 81.53 \\
\hline Sétimo decil & 23.61 & 32.79 & 11.10 & 70.17 \\
\hline Octavo decil & 21.19 & 27.31 & 8.55 & 59.53 \\
\hline Noveno decil & 13.86 & 18.61 & 4.98 & 41.55 \\
\hline Décimo decil & 7.35 & 9.84 & 2.62 & 20.93 \\
\hline Total & 36.71 & 52.29 & 30.57 & 75.31 \\
\hline
\end{tabular}

en el Decil más bajo de ingresos se encuentra fuertemente excluido al tener el 60,9\% excluidos de estos servicios, y sólo el 1,94\% tiene acceso a los tres.

\section{2. 4. Acceso a medios de comunicación y entretenimiento}

El cuadro 7 muestra los porcentajes de exclusión para aquellos hogares que no tienen acceso a los medios de comunicación o esparcimiento antes señalados, bajo los criterios de dominio geográfico, lengua materna y decil de ingresos. Como se puede 
Cuadro 6 - Exclusión Social según el Número de Servicios Básicos de la Vivienda al cual el Hogar tiene Acceso (En Porcentajes).

\begin{tabular}{|l|c|c|c|c|}
\hline \multicolumn{1}{|c|}{$\begin{array}{c}\text { CRITERIO DE } \\
\text { AGRUPACION }\end{array}$} & \multicolumn{4}{c|}{$\begin{array}{c}\text { Servicios Básicos de la Vivienda } \\
\text { (Agua, desague, Iuz) }\end{array}$} \\
\hline DOMINIO GEOGRAFICO & Ninguno & Al menos 1 & Al menos 2 & Al menos 3 \\
\hline costa norte & 20.93 & 19.83 & 13.73 & 45.51 \\
\hline costa centro & 15.37 & 13.92 & 16.42 & 54.29 \\
\hline costa sur & 2.16 & 16.83 & 25.00 & 56.01 \\
\hline sierra norte & 40.35 & 30.59 & 10.27 & 18.79 \\
\hline Sierra centro & 34.39 & 23.94 & 20.72 & 20.95 \\
\hline Sierra sur & 26.45 & 20.16 & 21.09 & 32.30 \\
\hline selva & 41.81 & 27.09 & 12.90 & 18.20 \\
\hline Lima metropolitana & 1.77 & 16.74 & 3.74 & 77.75 \\
\hline Total & $\mathbf{2 1 . 6 0}$ & $\mathbf{2 0 . 9 1}$ & $\mathbf{1 2 . 9 7}$ & $\mathbf{4 4 . 5 3}$ \\
\hline \multicolumn{1}{|c|}{ LENGUA MATERNA } & Ninguno & Al menos 1 & Al menos 2 & Al menos 3 \\
\hline castellano & 17.72 & 20.08 & 11.28 & 50.92 \\
\hline quechua & 30.50 & 23.84 & 17.76 & 27.90 \\
\hline aymara & 21.75 & 23.03 & 22.33 & 32.89 \\
\hline Otra lengua nativa & 74.64 & 16.84 & 0.97 & 7.56 \\
\hline inglés & 0.00 & 100.00 & 0.00 & 0.00 \\
\hline portugués & 0.00 & 0.00 & 0.00 & 100.00 \\
\hline Otro idioma extranjero & 3.55 & 6.83 & 0.00 & 89.62 \\
\hline es sordomudo & 17.85 & 82.15 & 0.00 & 0.00 \\
\hline Total DECIL & $\mathbf{2 1 . 7 2}$ & $\mathbf{2 1 . 0 8}$ & $\mathbf{1 3 . 1 3}$ & $\mathbf{4 4 . 0 7}$ \\
\hline & Ninguno & Al menos 1 & Al menos 2 & Al menos 3 \\
\hline Primer decil & 60.92 & 27.75 & 9.40 & 1.94 \\
\hline Segundo decil & 44.84 & 31.75 & 16.36 & 7.05 \\
\hline Tercer decil & 36.98 & 29.76 & 16.19 & 17.07 \\
\hline Cuarto decil & 22.77 & 28.82 & 17.54 & 30.86 \\
\hline Quinto decil & 20.85 & 23.85 & 16.76 & 38.55 \\
\hline Sexto decil & 11.85 & 20.42 & 18.22 & 49.52 \\
\hline Sétimo decil & 6.66 & 18.11 & 11.29 & 63.94 \\
\hline Octavo decil & 5.81 & 14.50 & 10.64 & 69.06 \\
\hline Noveno decil & 3.34 & 9.27 & 8.89 & 78.50 \\
\hline Décimo decil & 1.56 & 5.02 & 5.08 & 88.33 \\
\hline Total & $\mathbf{2 1 . 6 0}$ & $\mathbf{2 0 . 9 1}$ & $\mathbf{1 2 . 9 7}$ & $\mathbf{4 4 . 5 3}$ \\
\hline
\end{tabular}


observar, la radio y la televisión se han convertido en un medio masivo de comunicación ya que presenta los niveles más bajos de exclusión, menor al 9,69\% del conjunto de hogares analizados.

Por su parte, la compra de periódicos y revistas muestra porcentajes por encima del $50 \%$ de excluidos. Una de las razones podría deberse a los niveles de analfabetismo que hay en nuestro país, aunque esto no explica todo ya que hasta en los grupos con los deciles más elevados de ingresos existen personas que no acceden a este medio de comunicación. Quizás algunos hogares opten por no comprar el periódico y leerlo en su lugar de trabajo o en los quioscos, o simplemente reemplazar este medio escuchando la radio o la televisión, ya que son bienes sustitutos.

Finalmente, más de $75 \%$ de hogares a nivel nacional no destinan nada de sus ingresos a divertirse, lo cual tiene sentido al tratarse de un país con altos niveles de pobreza en los que la diversión es un lujo, y por lo tanto es escaso y caro.

\section{Cuadro 7 - Exclusión Social según el Acceso a Medios de Comunicación y Esparcimiento (En Porcentajes).}

\begin{tabular}{|c|c|c|c|}
\hline $\begin{array}{c}\text { DOMINIO } \\
\text { GEOGRAFICO }\end{array}$ & $\begin{array}{l}\text { Ni TV ni } \\
\text { Radio }\end{array}$ & Revistas & Diversión \\
\hline costa norte & 6.68 & 53.23 & 84.72 \\
\hline costa centro & 3.00 & 50.71 & 89.76 \\
\hline costa sur & 1.89 & 49.10 & 84.00 \\
\hline sierra norte & 13.61 & 88.69 & 93.57 \\
\hline sierra centro & 17.58 & 72.38 & 91.25 \\
\hline sierra sur & 6.61 & 70.32 & 87.88 \\
\hline selva & 26.48 & 72.07 & 90.60 \\
\hline Lima metropolitana & 2.16 & 40.55 & 77.68 \\
\hline Total & 9.69 & 59.96 & 85.93 \\
\hline LENGUA MATERNA & $\begin{array}{l}\text { Ni TV ni } \\
\text { Radio }\end{array}$ & Revistas & Diversión \\
\hline castellano & 8.34 & 54.02 & 83.40 \\
\hline quechua & 12.31 & 73.54 & 91.86 \\
\hline aymara & 5.83 & 73.20 & 90.28 \\
\hline otra lengua nativa & 66.25 & 88.21 & 99.01 \\
\hline inglés & 0.00 & 100.00 & 0.00 \\
\hline portugues & 0.00 & 75.81 & 100.00 \\
\hline otro idioma extranjero & 2.53 & 43.15 & 90.59 \\
\hline sordomudo & 100.00 & 100.00 & 100.00 \\
\hline Total & 9.81 & 60.20 & 86.07 \\
\hline DECIL & $\begin{array}{l}\text { Ni TV ni } \\
\text { Radio }\end{array}$ & Revistas & Diversión \\
\hline Primer decil & 31.9 & 93.44 & 97.08 \\
\hline Segundo decil & 20.62 & 90.3 & 96.64 \\
\hline Tercer decil & 12.71 & 83.44 & 94.5 \\
\hline Cuarto decil & 8.24 & 77.05 & 93.07 \\
\hline Quinto decil & 7.33 & 69.84 & 92.45 \\
\hline Sexto decil & 4.3 & 65.38 & 89.85 \\
\hline Sétimo decil & 3.38 & 59.47 & 88.32 \\
\hline Octavo decil & 2.48 & 55.71 & 87.58 \\
\hline Noveno decil & 2.52 & 44.63 & 84.63 \\
\hline Décimo decil & 1.24 & 32.4 & 67.84 \\
\hline Total & 9.69 & 59.96 & 85.93 \\
\hline
\end{tabular}




\section{CONCLUSIONES}

La exclusión social resulta relevante en cuanto las personas se ven privadas de algún bien o servicio; esta privación tiene un carácter multidimensional. Una manera de hacerlo es dando gran consenso para realizar estándares económicos de la pobreza, brindando atención a los procesos que llevan a las personas a la pobreza, dando luces de las causas de la pobreza crónica vs. la transitoria, a las razones por las cuales algunos grupos tienen dificultad para emerger de la pobreza mientras que otros encuentran fácil la movilización social.

Pobreza no es lo mismo que exclusión social, ni viceversa. Sin embargo, aquellas personas que se sienten excluidas de la sociedad son más vulnerables a caer en una situación de pobreza y permanecer en ella. En este sentido, conocer quiénes son las víctimas de este fenómeno de la exclusión social ayudará a los hacedores de política a focalizar sus esfuerzos, y contribuir a que cada vez existan menos personas que puedan sucumbir en la pobreza.

$\mathrm{Al}$ interior de la pobreza en el Perú, existe una fuerte heterogeneidad respecto no sólo de los niveles de ingreso, sino también, y de manera especial, de otras dimensiones como el acceso a la educación, salud, cultura, trabajo, y programas sociales. Debido a esta heterogeneidad de la pobreza y a las diferentes dimensiones de la exclusión y prioridades de la propia población, resulta necesario focalizar mucho más finamente las políticas de lucha contra la pobreza extrema y los programas sociales.

La evaluación de los programas y proyectos sociales desde la perspectiva de la exclusión social permite nuevos criterios para estimar su impacto y sobre todo su sostenibilidad (8). Superar, en este punto, la exclusión social supone no solamente disminuir las carencias, aumentando y mejorando lainfraestructura por ejemploen salud, saneamiento; sino desarrollar y promover la educación, proveer nuevas capacidades y conocimientos y sobre todo la creación y promoción de una integridad nacional en la que se acepten y reconozcan las diferencias raciales y culturales y éstas sean consideradas al momento de diseñar políticas de alivio de la pobreza e inclusión social. De esta manera, un criterio adicional para la evaluación de políticas debe ser su contribución a la inclusión social (9).

(8) Los programas orientados al desarrollo de capacidades deben fomentar la auto-confianza y valorizar las iniciativas propias para superar la pobreza, evitando así una "cultura de la dependencia" y su correlato, el asistencialismo. Pocos programas oficiales de alivio de la pobreza han enfatizado y priorizado la inversión en el capital humano y el fortalecimiento de las organizaciones locales otorgándoles las herramientas necesarias para que superen su estado de pobreza por sí mismos de manera sostenible en el tiempo.

(9) La evaluación más frecuente de los programas sociales se ha basado en la forma en que son ejecutados (su eficiencia) y cómo llegan a los beneficiarios y quiénes son estos (su eficacia). Sin embargo, no todos los pobres dentro de la sociedad se ven favorecidos por un programa social. Se puede decir que los que no reciben esta ayuda están siendo socialmente excluidos por el gobierno. El problema es que, por ejemplo, puede existir una pequeña comunidad muy pobre pero que no justifica una inversión en ella porque justamente es muy pequeña. Por lo tanto, el Estado se va a encargar de ayudar a otras dejándola excluida: no tiene acceso a los beneficios que le competen como grupo "pobre". En este sentido es relevante la participación de grupos filantrópicos o iniciativas voluntarias del tercer sector para promover el desarrollo de estos grupos vulnerables y excluidos. Por ejemplo a través de proyectos de responsabilidad social en las empresas o asociaciones voluntarias, o la creación de redes comunitarias. 
Existe una estrecha relación entre pobreza y exclusión social aunque las dimensiones de la exclusión pueden variar significativamente al interior de los diversos grupos que componen la sociedad, incluyendo a los grupos de pobreza extrema. En este sentido, la importancia de determinar quiénes se han visto excluidos y de qué manera han sido y están siendo afectados, debe ser reconocida y calculada. De igual modo, se plantea la necesidad de saber de qué están siendo excluidos y cuáles son las medidas y programas que puedan contribuir a disminuir los niveles de exclusión social.

El presente documento deja en claro ciertos aspectos respecto de la exclusión social en el Perú:

- Las mujeres presentan índices de exclusión más altos que los hombres en el caso de la educación.

- Las personas que viven en la Sierra presentan los índices de exclusión más altos a nivel nacional.

- Los índices más bajos de exclusión se encuentran en Lima Metropolitana.

- La exclusión del esparcimiento y diversión es muy alta (mayor a 50\% en todos los dominios geográficos, etnia y nivel de ingresos).

- Poblaciones no consideradas pobres al ser medidas en términos de ingreso están excluidas de la educación y la salud, por lo que constituyen un grupo vulnerable susceptible de caer en estado de pobreza.

- Los pobres y además excluidos, son extremadamente vulnerables en la medida que pueden estar entrampados en la pobreza y transmitirla a futuras generaciones.

- Estos grupos vulnerables deben recibir especial atención en pos de superar su estado mediante programas integrales de inclusión. Por ejemplo, no basta con promover el acceso a servicios de salud sino dar paralelamente educación ya que, de lo contrario, no utilizaran los servicios de salud debido a factores culturales.

Si bien, la exclusión social en un país como el Perú no concierne aspectos como el desempleo en la magnitud en la que ocurre en países desarrollados (existe el empleo informal y subculturas), involucra otros aspectos como la fuerte exclusión en las provincias al acceso a educación, salud y otros. Ello se explicaría en gran medida por el hecho de que el Perú es un país altamente centralizado, lo cual se refleja en las grandes diferencias entre los niveles de exclusión en Lima Metropolitana respecto del resto del país, aun cuando en Lima hay un alto nivel de inmigrantes de las provincias.

Este trabajo muestra claramente que en un país en desarrollo como el Perú, la exclusión ocurre en términos del consumo de servicios básicos, educación y salud. Resulta importante determinar si la exclusión ocurre por factores de ingreso, zona geográfica, educación y/o étnicos. En este sentido, se haidentificado una alta correlación entre zona geográfica, etnia y niveles de ingreso, y la exclusión de estos respecto de los servicios básicos, la educación y la salud.

En zonas geográficas de la Sierra y la Selva, la provisión de servicios es limitada en cuanto no se cuenta con la infraestructura suficiente, pero además está fuertemente presente el factor cultural. Muchas personas señalan que la discriminación étnica es mínima, que se trata más bien de razones de educación que impiden una integración 
cultural mayor. Sin embargo, ello no se ha observado en la práctica en aquellas personas que han logrado a través del mercado generar riqueza pero tienen un origen "humilde". En este sentido, se estaría frente a una exclusión étnica con implicaciones psicológicas para los excluidos.

Por otro lado, en la medida que mejoren las oportunidades para desarrollarse e integrarse al mercado para las personas que viven en zonas geográficas más alejadas a través de un mayor capital social, se reducirán los niveles de pobreza y aumentará la movilidad social. Ello tendrá impactos económicos y culturales, en la medida que la educación en el Perú, es actualmente beneficio de una élite.

\section{Referencias citadas}

ALDAZ-CARROL, E. \& MORAN, R., 1999 - Family Factors in the Intergenerational Transmission of Poverty: Empirical results and policy implications for Latin America: 2-4; University of Sussex.

ALTAMIRANO, T., 1990 - Los que se fueron. Peruanos en Estados Unidos. Lima: PUCP.

ARAMBURÚ, C. \& FIGUEROA, C., 1999 - ¿Cómo Reducir la Pobreza y la Inequidad en América Latina?, 84.

ARJAN, H. de, 1997 - Poverty and Social Exclusion: a New Research Agenda, Página Web: www.ids.ac.uk/ids/.

ATKINSON, T. \& HILLS, J., 1998 - Exclusion, Employment and Opportunity, 13; London: Centre for Analysis of School Exclusion.

BANCO MUNDIAL, 2000 - La Voz de los Pobres: ¿Hay Alguien que nos Escuche?

BANCO MUNDIAL, 2001 - Informe sobre el Desarrollo Mundial 2000/2001, Lucha Contra la Pobreza, Panorama General.

BOURGIGNON, F., 1999 - Absolute poverty, relative deprivation and social exclusion, Villa Borsig Workshop series: 3.

BRACK \& MORA, 1998 - Atlas de Comunidades Nativas del Perú. Lima : Defensoría del Pueblo.

BRITTON, A., 1998 - Employment and Social Cohesion. 28; London: Center of Analysis of Social Exclusion.

DAS GUPTA, M., 1999 - Social Exclusion and Poverty: Preliminary Thoughts for the World Development Report 2001, Villa Borsig Workshop Series.

ENAHO, 2001 - Encuesta Nacional de Hogares realizada por el INEI en el IV trimestre del 2001.

GALLIE, D., 1998 - Unemployment and Social excusion in the European Union. In: Reform and the Social Contract. London: Queens University.

GARCÍA NIETO, J., 1987 - Pobreza y Exclusión social, 14-15; España: Fundación Luis Espinal.

GROOTAERT, C., 1998 - Social capital: The missing link?, IRIS: www.powerty.worldbank.org/ library/view/5459 
HAQ, M. U., 1992 - Human Development in a Changing World, 1; UNDP. ocasional paper1. HERRERA, J., 2002 - La pobreza en el Perú en 2001: una visión departamental, 196p.; Lima: INEI.

HICKS, P., 1998 - A New Social Policy Paradigm?. The case of ageing and Policy-Making. In: Reform and the Social Contract. London: Queens University.

KAMBUR, R. \& SQUIRE, L., 1999 - The Evolution of Thinking About Poverty: Exploring the Interactions: 1. Washington: Banco Mundial.

PAUGAM, S., 2000 - La disqualification sociale. Paris: Presses Universitaires de France.

PNUD, 1997. Powerty and social deprivation: el reporte de Desarrollo humano de Estonia.

SEN, A., 1987 - The standard of living, Cambridge: Cambridge University Press.

UNICEF, 2000 - Poverty Reduction Begins With Children: 6; New York.

UNIVERSITY OF DURHAM, 1995 - Social Exclusion, Social Inclusion, In: Democratic Dialogue: 1; Reino Unido: University of Durham.

UNIVERSITY OF DURHAM, Introduction en Study of Local Initiatives to combat social exclusion in Europe, Reino Unido: University of Durham.

UNIVERSITY OF DURHAM, Social exclusion in the UK, Study of Local Initiatives to combat social exclusion in Europe, Página Web, Reino Unido: University of Durham. 
